\title{
Research is the future: get involved
}

\author{
Fiona Godlee editor in chief
}

The BMJ

Research and journalism can work together to achieve better outcomes for patients. In 2013 The BMJ published a feature on the fashionable practice of sentinel node biopsy in people with malignant melanoma (doi:10.1136/bmj.e8645). The journalist Ingrid Torjesen reported that follow-up data from a key clinical trial had not been published. Her article prompted a commentary in the British Journal of Dermatology raising doubts about the benefits of sentinel node biopsy (doi:10.1111/bjd.12487). When the long awaited data were eventually published in the New England Journal of Medicine last year (doi:10.1056/ NEJMoa1310460), specialty journals ran further critical comment.

Now an editorial in The BMJ confirms the view that sentinel node biopsy confers no survival advantage except perhaps in a small minority of patients (doi:10.1136/bmj.h5940). "Any apparent benefit in disease-free survival is clearly a result of trial design and mislabelling of patients," say Michael Bigby and Catalin Popescu.

Clinical research, properly done and fully and openly reported, is essential to improving the care of patients. Karl Claxton and colleagues (doi:10.1136/bmj.h5987) explain how meta-analysis can help us decide whether more research is needed and when to implement existing research. And we also ask whether, as the UK's National Institute of Health Research believes, clinicians' involvement in research is as important as treating patients (doi:10.1136/bmj.h6329). This may seem impossible, given the increasing pressure of patient care. But, as Anne Gulland reports, the institute's clinical research networks are there to support UK clinicians, and the institute is using its funding power to actively promote women researchers.

More than three million NHS patients took part in research over the past five years. Bravo. Now let's make sure that patients are properly involved, not just as participants but in trial conception, design, and conduct and the analysis, reporting, and dissemination of results. You may have noticed the new "patient involvement" box in The BMJ's research articles. Sadly, all too often the text reads something like, "No patients were involved in setting the research question or the outcome measures; nor were they involved in the design and implementation of the study. There are no plans to involve patients in the dissemination of results." We hope that the shock of such statements will stimulate change. Examples of good patient involvement will also help: see the multicentre randomised trial on stepped care for depression and anxiety (doi:10.1136/bmj.h6127).

Our plan is to shine a light on the current state of affairs and then gradually raise the bar. Working with other journals, research funders, and ethics committees, we hope that at some time in the future only research in which patients have been fully involved will be considered acceptable.

Cite this as: BMJ 2015;351:h6525

(๑) BMJ Publishing Group Ltd 2015 